\title{
A Inter-relação do artesanato tradicional com a Mata Atlântica e seus ecossistemas associados na Rota Turística do Verde e das Águas (ES)
}

\author{
Mário Vinícius Cinelli Zanetti, Ubirajara Corrêa Nascimento
}

\section{RESUMO}

O objetivo geral deste estudo foi catalogar as matérias-primas oriundas da flora local da Mata Atlântica na Rota Turística do Verde e das Águas (ES), composto pelos municípios de Vitória, Aracruz, Linhares, São Mateus e Conceição da Barra. Foram definidas as seguintes metas: 1. Identificar amostras de peças artesanais produzidas pelos artífices da Rota, sendo 1 (um) artesão (a) por município; 2. Elencar as matérias-primas extrativistas oriundas da Mata Atlântica e de seus Ecossistemas Associados e 3. Propor ações de valorização do artesanato tradicional através do desenvolvimento do Ecoturismo. A metodologia utilizada foi: Pesquisa de Gabinete; Visitas de Campo; Tabulação de Dados e Formatação dos Resultados; Redação Final e Publicação dos Resultados. A partir da análise das informações obtidas nas entrevistas foi possível identificar que em grande parte, as matérias-primas são coletadas nas áreas de cobertura vegetal caracterizadas pela Mata Atlântica, a Restinga e o Manguezal. Ao final do estudo, foi concluído o levantamento textual do artesanato local (embasado na metodologia apresentada) e suas respectivas matériasprimas utilizadas pelos artesãos entrevistados. Sugerem-se como intervenções: mobilizar e sensibilizar os moradores, turistas e visitantes no que se refere à preservação ambiental; assegurar o desenvolvimento econômico local através do desenvolvimento da cultura, do meio ambiente e do turismo; propor ações de Educação Ambiental além de outras ações necessárias para o desenvolvimento local e a preservação da natureza.

\section{Inter-relationship of traditional craftsmanship with the Atlantic Forest and associated ecosystems in the 'Tourist Route of the Green and Water', Espírito Santo, Brazil}

\begin{abstract}
The aim of this study was to catalog the materials originated from the local flora of the Atlantic Forest in Tourist Route of Green and Water (ES, Brazil), composed of the municipalities of Vitoria, Aracruz, Linhares, São Mateus and Conceição da Barra. The following goals were defined: 1. To identify samples produced by craftsmen of the Route, 1 craftsman by municipality; 2 . Relate the extractivist raw materials from the Atlantic Forest and associated ecosystems and 3. Propose actions for the recovery of traditional crafts through the development of Ecotourism. The methodology used was: Research Office, Field Visits, Data Tab and Formatting of Results; Writing and Publication of Final Results. From the analysis of information obtained in interviews it was possible to identify that a large extent of raw materials are collected in the areas of vegetation characterized as the Atlantic Forest, restinga and mangrove. At the end of the study the textual survey of local crafts who were interviewed (grounded in the methodology presented) and their raw materials was completed. Measurements are suggested: mobilize and sensitize the residents, tourists and visitors into the environmental preservation, and ensure local economic development through the development of culture, environment and tourism; by proposing actions to promote environmental education or other activities necessary for local devel.
\end{abstract}

KEYWORDS: Crafts, Environment, Tourism. 
A inter-relação do artesanato tradicional com a Mata Atlântica na Rota Turística do Verde e das Águas (ES)

\section{Introdução}

Há muito tempo o mundo inseriu em sua pauta de conversações a temática ambiental como uma de suas diretrizes para orientar diversas questões na interrelação entre os países. As políticas públicas dos governos em âmbito federal, estadual e municipal no Brasil já têm trabalhado em seus órgãos internos e com as comunidades diversos programas, projetos e ações com vistas a minimizar os impactos ambientais causados pelas intervenções humanas na natureza.

Constantemente encontra-se na mídia a exposição de termos como a sustentabilidade ambiental, consciência ambientalista, preservação da flora e fauna além dos recursos hídricos e minerais existentes no Brasil com vistas a atrair a atenção da população quanto à importância de valorizar as ações que buscam mitigar a constante busca de elementos da natureza para o consumo humano.

Desde idos do século XVI existe a exploração de recursos naturais expressa na retirada de pau-brasil na costa brasileira, sendo este o primeiro item visado pelos portugueses. Posteriormente, com a chegada dos donatários, a faixa litorânea recebeu uma tentativa inicial de investimento, com a intervenção na Mata Atlântica e em seus Ecossistemas Associados ${ }^{1}$, sofrendo desde modo grande perca de cobertura vegetal.

A partir de dados disponibilizados pelo INSTITUTO BIOATLÂNTICA (2009, s/p) tem-se que

A área geográfica que compreende a Mata Atlântica e seus ecossistemas associados - manguezais e restingas na costa, o ambiente marinho e áreas de transição com Cerrado e Caatinga no continente - é hoje uma das regiões mais ameaçadas no mundo pela ocupação e atividade humanas. Originalmente a Mata Atlântica cobria mais de 1,3 milhões de $\mathrm{km}^{2}$. Atualmente, restam apenas cerca de $8 \%$ de sua cobertura florestal original. A história e a vida econômica do Brasil estão fortemente relacionadas à Mata Atlântica, que está distribuído por 17 estados, onde são produzidos $80 \%$ do Produto Interno Bruto (ou seja, $80 \%$ do valor da produção industrial e dos serviços do país) e vivem $70 \%$ de sua população total. Tanto as atividades econômicas quanto a população, de maneira geral, dependem diretamente dos recursos naturais que são produzidos ou regulados pela Mata Atlântica.

De acordo com o Ministério do Meio Ambiente, a Mata Atlântica e seus ecossistemas associados

envolviam, originalmente, uma área de $1.360 .000 \mathrm{~km}^{2}$, correspondente a cerca de $16 \%$ do território brasileiro e distribuídos por 17 Estados: Rio Grande do Sul, Santa Catarina, Paraná, São Paulo, Goiás, Mato Grosso do Sul, Rio de Janeiro, Minas Gerais, Espírito Santo, Bahia, Alagoas, Sergipe, Paraíba, Pernambuco, Rio Grande do Norte, Ceará e Piauí. Devido a séculos de destruição ambiental, o bioma foi reduzido a me- 
nos de $8 \%$ de sua extensão original, dispostos de modo esparso, ao longo da costa brasileira e no interior das regiões Sul e Sudeste, além de fragmentos no sul dos Estados de Goiás e Mato Grosso do Sul e no interior dos estados do Nordeste. A dinâmica da destruição foi mais acentuada durante as últimas três décadas, resultando em sérias alterações para os ecossistemas que compõem o bioma, devido, em particular, à alta fragmentação do hábitat e perda de sua biodiversidade. Ao longo de toda sua extensão, a Mata Atlântica apresenta uma variedade de formações, engloba um diversificado conjunto de ecossistemas florestais com estruturas e composições florísticas bastante diferenciadas, acompanhando as características climáticas da vasta região onde ocorre, tendo como elemento comum a exposição aos ventos úmidos que sopram do oceano (BRASIL, s/d, s/p).

Posteriormente o plantio de cana-de-açúcar, café e a mineração aliado com o processo de industrialização, urbanização e a especulação imobiliária da faixa litorânea promovidas sistematicamente, prejudicaram em muito a cobertura vegetal original existente, neste caso particular, em todo o território do Estado do Espírito Santo.

Percebe-se, a partir dos fatos históricos, que o litoral foi o ponto de partida para a exploração local, e que passados cinco séculos, ainda sofre com problemas oriundos da má gestão do aproveitamento dos recursos naturais e da demanda originada pelas comunidades existentes. Para este estudo de caso, optou-se por analisar "A inter-relação do Artesanato Tradicional e a Mata Atlântica e seus Ecossistemas Associados na Rota Turística do Verde e das Águas no Estado do Espírito Santo".

A divisão político-administrativa do território capixaba ${ }^{2}$ em 2009 compreende 78 municípios divididos em 12 microrregiões conforme registrado nos mapas do Instituto Jones dos Santos Neves - IJSN. Para fins de organização, a Secretaria de Estado do Turismo - SETUR - tem desenvolvido junto com a iniciativa privada e a Sociedade Civil Organizada as Rotas Turísticas ${ }^{3}$ diversas ações com vistas a fomentar o fluxo de turistas e visitantes aos municípios capixabas.

Conforme o que estabelece o Programa de Regionalização do Turismo - Roteiros do Brasil do Ministério do Turismo - Mtur (BRASIL, 2005, p.3 )

As orientações para elaboração de roteiros turísticos são importantes para que se inicie de forma organizada, o processo de roteirização, o que subsidiarÁ o fortalecimento dos vários processos já existentes, nas diversas regiões turísticas. Estas Possuem caráter norteador e devem ser acolhidas dentro do princípio da flexibilidade.

A partir da reflexão quanto ao crescimento do fluxo turístico, faz-se importante conhecer o contexto dos artífices e seu artesanato em relação à preservação ambien- 
tal da Mata Atlântica e de seus Ecossistemas Associados. Sendo assim é necessário demonstrar a importância do desenvolvimento de atividades econômicas extrativistas e do Turismo a partir do viés da sustentabilidade de modo a reduzir os impactos na natureza.

A atividade turística possui diversos segmentos que variam conforme o tipo de atividade desenvolvida nas viagens, sobretudo o objetivo de cada indivíduo. Denomina-se esse processo de Segmentação do Turismo ${ }^{4}$, como por exemplo, Turismo Religioso, Turismo Cultural, Turismo de Eventos, Turismo Histórico, Turismo Esportivo, dentre outros, que por sua vez não são excludentes entre si. Devido à magnitude que o turismo conquistou no contexto socioeconômico, é considerado uma indústria "limpa", que gera importantes divisas sem poluir ou danificar o ambiente. Esta é uma afirmação que merece uma avaliação mais delicada, pois se sabe que o turismo de massa não controlado e sem planejamento é capaz de degradar a estrutura sócioambiental local de maneira bastante crítica (BRASIL, 2005).

Um importante vertente do turismo que tem crescido muito rapidamente nos últimos anos é o Ecoturismo que de acordo com o Ministério do Turismo (BRASIL, 2008, p.16)

é um segmento da atividade turística que utiliza, de forma sustentável, o patrimônio natural e cultural, incentiva sua conservação e busca a formação de uma consciência ambientalista por meio da interpretação do ambiente, promovendo o bem-estar das populações.

Com uma propagação rápida entre os adeptos, principalmente jovens, o Ecoturismo passou a ser desenvolvido de maneira muito aleatória, quase sempre utilizando as Unidades de Conservação brasileiras como espaço turístico, mas sem qualquer regulamentação técnica e legal, por meio de diretrizes que estabelecessem sua real função e princípios.

É importante dizer que a atividade turística tem propiciado diversos impactos ambientais e socioeconômicos, principalmente nos locais que não conhecem ou aplicam as diretrizes de preservação ambiental proposto em diversas instâncias de governo e da sociedade civil brasileira.

O Ecoturismo tende a crescer bastante no Brasil nos próximos anos, pois a cada dia percebe-se que seus atrativos são realmente interessantes e merecem destaque, no entanto, espera-se que esta atividade caminhe paralelamente a um excelente planejamento, seguido de uma boa gestão e recursos financeiros necessários, para que num futuro bastante próximo, seja possível contar com uma atividade ecoturística no Brasil mais responsável, que envolva as comunidades tradicionais, valorize e respeite seus devidos modos de vida e utilize os recursos naturais de forma adequada, pois estes, na verdade, são os próprios atrativos turísticos do local.

Uma das maneiras de potencializar os impactos positivos do Ecoturismo, conforme afirmado pelo Mtur (BRASIL, 2008, p. 53) e a 
valorização da diversidade cultural nas viagens, que enfatiza os saberes e fazeres e a identidade cultural na experiência turística que, antes de tudo, é uma experiência cultural. Entre essas vivências destacam-se as artes, o artesanato, a gastronomia típica, os sítios históricos, as danças, as músicas, o folclore, os museus. A história, os costumes, o cotidiano da comunidade são, também, fontes de aprendizado e experiência cultural para o turista, proporcionando o intercâmbio entre a comunidade e o turista. Essa vivência cultural pode ser incorporada ao segmento de Ecoturismo por meio de visitação a atrativos turísticos culturais ou à incorporação e valorização desses elementos de identidade local na oferta de serviços de alimentação, de hospedagem, de recreação e outras atividades, tais como oficinas de arte e ofícios. Para que isso ocorra de forma autêntica para o turista e com o devido respeito à cultura local, pressupõe que a comunidade deve participar do processo de planejamento do segmento, assinalando os aspectos importantes e significativos no seu cotidiano, na sua história.

A partir do processo de Roteirização promovido pela SETUR ${ }^{5}$, optou-se em promover o estudo nos municípios componentes da Rota do Verde e das Águas que compreende: Vitória, Aracruz, Linhares, São Mateus e Conceição da Barra.

De acordo com o site institucional do Governo do Estado do Espírito Santo temos que

Vitória é o ponto de partida para as Rotas Turísticas Capixabas devido sua infraestrutura de logística pelos modais rodoviários, ferroviário, portuário e aéreo. A capital Congrega em seu território manguezais, Unidades de Conservação, rico patrimônio histórico, artístico e cultural. A 50 $\mathrm{km}$ da capital, encontra-se o município de Aracruz que, cercada de atrativos naturais, abriga reservas das tribos Tupiniquins e Guarani, que comercializam seu artesanato. A seguir, tem-se Linhares, município conhecido como Paraíso das Águas, que abriga 25\% das reservas de Mata Atlântica do Estado e 64 lagoas que formam o maior complexo lacustre da Região Sudeste, tendo como principal a Lagoa Juparanã, com 38 $\mathrm{km}$ de extensão. Mais ao norte chega-se a São Mateus que tem à disposição do turista um rico patrimônio histórico/cultural. Nesse município está situado o Porto de São Mateus cujo entorno possui 32 sobrados, construídos nos séculos XVII e XIX e tombados pelo Patrimônio Histórico e Artístico Nacional, que remetem o turista à época da aristocracia rural. No litoral, a ilha de Guriri, uma das maiores do Estado, anexada ao continente por uma ponte sobre o rio Mariricu, é o principal ponto turístico. Para completar a rota Conceição da Barra, a capital capixaba do forró, reúne dunas, praias, que apresentam piscinas na baixa da maré, e agrestes. No município também acontece o famoso Baile de Congo, um auto teatral popular com duração de uma semana. A festa conhecida como Ticumbi retrata a luta entre Reis de Bamba e Reis de Congo, que disputam o privilégio de promover a festa em homenagem a 
São Benedito. O distrito de Itaúnas destaca-se como um importante conjunto turístico do município, guardião do Parque Nacional de Itaúnas, criado em 1991 que preserva uma variedade de ecossistemas integrados a fauna e a flora que lhe deu o título de Patrimônio da Humanidade concedido pela UNESCO que contempla dunas de até 30 metros de altura. Um lençol arenoso soprado pelo vento nordeste invadiu casas e cresceu progressivamente soterrando o primitivo núcleo populacional iniciado há mais de 300 anos (ESPÍRITO SANTO, s/d-b, s/p).

\section{Objetivos}

A partir do objetivo geral da pesquisa caracterizada por catalogar as matériasprimas oriundas da flora local a partir do levantamento de dados norteados através da "inter-relação do Artesanato Tradicional e a Mata Atlântica e seus Ecossistemas Associados na Rota Turística do Verde e das Águas no Estado do Espírito Santo" foram elencadas as seguintes metas:

- Identificar amostras de peças artesanais produzidas artícifes da Rota do Verde e das Águas no Estado do Espírito Santo, sendo 1 (um) artesão (a) por município;

- Elencar as matérias-primas de viés extrativista oriundas da Mata Atlântica e de seus Ecossistemas Associados e

- $\quad$ Propor ações de valorização do artesanato tradicional através do desenvolvimento do Ecoturismo com vistas à sensibilização ambiental, da viabilidade econômica, da preservação dos costumes e das tradições das comunidades locais.

\section{Metodologia}

A metodologia utilizada durante o desenvolvimento da pesquisa foi norteada pelas seguintes atividades:

A - Pesquisa de Gabinete: elaborada a partir de material já publicado, constituído principalmente de livros, artigos de periódicos e materiais selecionados na Internet;

B - Visitas de Campo: promovido aos artesãos que atuam em municípios da Rota do Verde e das Águas a partir da observação da Distribuição da Atividade Artesanal por Microrregião e Município constante no Atlas Folclórico do Brasil - Espírito Santo (INSTITUTO NACIONAL DO FOLCLORE, 1982) o seguintes municípios (Tabela 1): 
Tabela 1: Distribuição da Atividade Artesanal por Microrregião e Município

\section{a. microrregião Vitória}

\begin{tabular}{|l|c|c|c|c|c|c|c|c|c|c|c|}
\hline \multicolumn{1}{|c|}{ MUNICÍPIOS } & A & B & C & D & E & F & G & H & I & J & K \\
\hline Cariacica & 1 & 4 & 13 & 2 & 0 & 0 & 4 & 6 & 24 & 1 & 55 \\
\hline Serra & 1 & 1 & 21 & 4 & 2 & 1 & 8 & 28 & 35 & 1 & 102 \\
\hline Viana & 0 & 0 & 4 & 1 & 0 & 0 & 2 & 2 & 5 & 0 & 14 \\
\hline Vila Velha & 0 & 0 & 23 & 2 & 4 & 0 & 4 & 21 & 28 & 2 & 84 \\
\hline Vítória & $\mathbf{0}$ & $\mathbf{1 2}$ & $\mathbf{1 1}$ & $\mathbf{1}$ & $\mathbf{4}$ & $\mathbf{0}$ & $\mathbf{0}$ & $\mathbf{8}$ & $\mathbf{4 1}$ & $\mathbf{4}$ & $\mathbf{8 1}$ \\
\hline Total & 2 & 17 & 72 & 10 & 10 & 1 & 18 & 65 & 133 & 8 & 336 \\
\hline
\end{tabular}

b. microrregião Baixada Espírito-Santense

\begin{tabular}{|l|c|c|c|c|c|c|c|c|c|c|c|}
\hline \multicolumn{1}{|c|}{ MUNICÍPIOS } & A & B & C & D & E & F & G & H & I & J & K \\
\hline Aracruz & $\mathbf{0}$ & $\mathbf{1}$ & $\mathbf{1}$ & $\mathbf{0}$ & $\mathbf{0}$ & $\mathbf{0}$ & $\mathbf{3}$ & $\mathbf{6}$ & $\mathbf{1 2}$ & $\mathbf{0}$ & $\mathbf{3 0}$ \\
\hline Conceição da Barra & $\mathbf{0}$ & $\mathbf{4}$ & $\mathbf{1 6}$ & $\mathbf{1}$ & $\mathbf{0}$ & $\mathbf{0}$ & $\mathbf{4}$ & $\mathbf{3}$ & $\mathbf{5}$ & $\mathbf{0}$ & $\mathbf{3 3}$ \\
\hline Fundão & 0 & 0 & 9 & 1 & 0 & 0 & 0 & 0 & 8 & 1 & 19 \\
\hline Linhares & $\mathbf{0}$ & $\mathbf{0}$ & $\mathbf{2}$ & $\mathbf{2}$ & $\mathbf{0}$ & $\mathbf{0}$ & $\mathbf{7}$ & $\mathbf{1}$ & $\mathbf{2}$ & $\mathbf{1}$ & $\mathbf{1 5}$ \\
\hline Pinheiros & 0 & 4 & 7 & 2 & 2 & 1 & 0 & 2 & 12 & 0 & 30 \\
\hline São Mateus & $\mathbf{0}$ & $\mathbf{4}$ & $\mathbf{3 5}$ & $\mathbf{6}$ & $\mathbf{4}$ & $\mathbf{0}$ & $\mathbf{6}$ & $\mathbf{6}$ & $\mathbf{3 0}$ & $\mathbf{0}$ & $\mathbf{9 1}$ \\
\hline Total & 0 & 13 & 77 & 12 & 6 & 1 & 20 & 18 & 69 & 2 & 218 \\
\hline
\end{tabular}

\section{Legenda}

A - Tecelagem, B - Cerâmica, C - Fibras e Trançados, D - Couros e Peles, E - Metal, F Coco, G - Madeiras, H - Implementos de Caça e Pesca, I - Rendas, Bordados e Congêneres, J - Outros, K - Total

Fonte: Atlas Folclórico do Brasil - Espírito Santo

C - Tabulação de Dados e Formatação dos Resultados: organização dos dados obtidos na pesquisa de campo subsidiada pelo Instrumento de Pesquisa para dar suporte à elaboração de índices e cálculos estatísticos, tabelas, quadros e gráficos, conforme o caso;

D - Redação Final: A redação final tem a proposta de organizar as informações de modo a atender aos objetivos da pesquisa e para comparar e confrontar dados e provas com o objetivo de confirmar ou rejeitar a(s) hipótese(s) ou os pressupostos da pesquisa e

E - Publicação dos Resultados: divulgação dos dados obtidos através de periódicos ou similares com o objetivo de socializar as informações coletadas. 


\section{Resultados e Discussão}

Para iniciar os trabalhos, foram coletadas referências teóricas para embasar e nortear a pesquisa. A preocupação inicial foi a de identificar o conceito de Desenvolvimento Sustentável do Turismo, o qual é definido por Ruschmann (1997) como aquele que atende às necessidades dos turistas atuais, sem comprometer a possibilidade do usufruto dos recursos das gerações futuras

A inter-relação entre o Turismo e o Meio Ambiente é justificada a partir por Ruschmann (1997, p. 19) na visão que o

último constitui a "matéria-prima" da atividade. A deteriorização das condições de vida nos grandes conglomerados urbanos faz com que um número cada vez maior de pessoas procurem nas férias e nos fins de semana as regiões com belezas naturais. O contato com a natureza constitui, atualmente, uma das maiores motivações nas viagens de lazer e as consequências do fluxo de massa de turistas para esses locais - extremamente sensíveis, tais como as praias e as montanhas - devem ser necessariamente ser avaliadas e seus efeitos negativos, evitados, antes que este valioso patrimônio da humanidade se degrade irremediavelmente.

Outro destaque registrado por Moura (2008, p.1) é

que a demanda global por recursos naturais deriva de uma formação econômica cuja base é a produção e o consumo em larga escala. A lógica associada a essa formação é responsável por boa parte da destruição dos recursos naturais e é criadora de necessidades que exigem, para sua própria manutenção, um crescimento sem fim das demandas quantitativas e qualitativas desses recursos. Sabe-se que a criação de necessidades humanas é infinita e ilimitada. Já os recursos naturais, que são os meios com os quais a sociedade conta para efetuar a fabricação de bens para satisfazer a essas necessidades, são finitos e limitados.

(...) Surgem assim, diversas teorias e propostas a respeito de como conciliar a necessidade de crescimento econômico (satisfação das supostas necessidades humanas) com a necessidade de preservação do patrimônio natural e cultural da humanidade.

Posteriormente, foi necessário utilizar um conceito para viabilizar a elaboração do instrumento de pesquisa para coleta de dados, o que foi embasado na "Instrução Normativa $n^{\circ} .2$ do Artesanato Capixaba" editado pela Secretaria de Estado do Traba- 
Iho, Assistência e Desenvolvimento Social - SETADES ${ }^{6}$ que e seu Art. $3^{\circ}$ Inciso II, diz que

Artesanato é o conjunto de objetos utilitários e decorativos para o cotidiano do homem, resultante da transformação da matériaprima, com predominância manual, por um indivíduo que detenha o domínio integral de uma ou mais técnicas previamente conceituadas, aliando criatividade, habilidade e valor cultural, com ou sem expectativa econômica, podendo no processo ocorrer o auxílio limitado de máquinas, ferramentas, artefatos e utensílios (ESPÍRITO SANTO, 2009, pg. 3).

A partir da metodologia proposta pelos pesquisadores, foram realizadas entrevistas com artesãos que atuam nos municípios da Rota do Verde e das Águas sendo: uma paneleira do bairro de Goiabeiras em Vitória, um membro da comunidade indígena de Aracruz e artífices residentes em Linhares, São Mateus e Conceição da Barra (um por localidade). As informações coletadas foram registradas e posteriormente compiladas o qual foi possível obter as seguintes ponderações:

Ao analisar os dados referentes às entrevistas realizadas nos municípios da "Rota do Verde e das Águas" identificou-se que não houve índice para a classificação "Não Alfabetizados", que 60\% tem somente "Ensino Fundamental, 20\% tem Ensino Médio e 20\% Ensino Superior (Tabela 2).

Tabela 2:

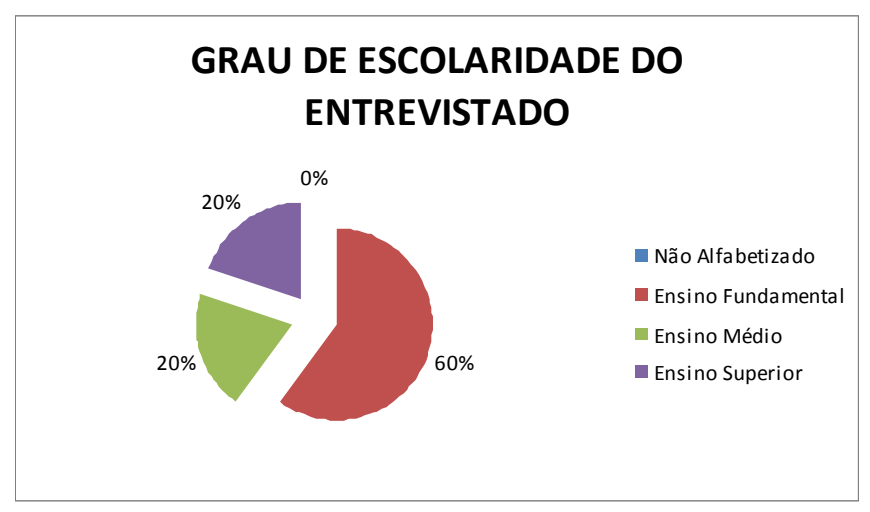

O levantamento destaca que o saber é difundido em sua grande maioria na classificação "Independente do Sexo" com 80\% (Tabela 3). 
Tabela 3:

O SABER É TRADICIONALMENTE DIFUNDIDO ENTRE:

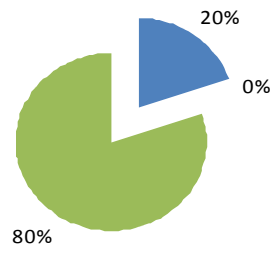

- Homens

Mulheres

Independente do Sexo

Destaca-se no item Produção que $60 \%$ ocorre na modalidade Individual e $40 \%$ Coletiva (Tabela 4).

Tabela 4:

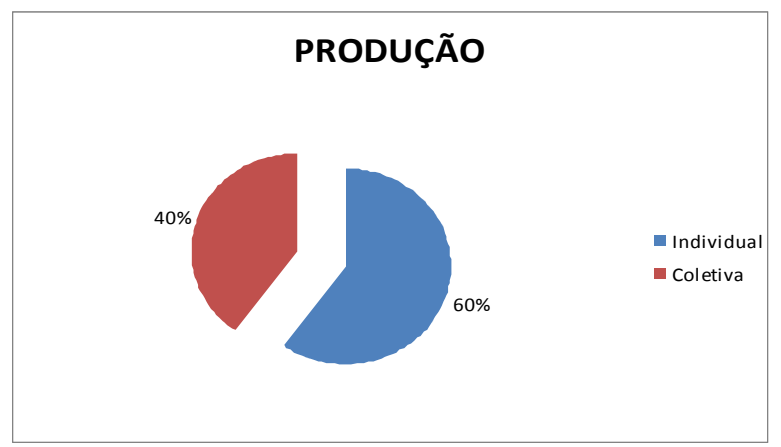

Para o questionamento que interrelaciona diretamente ao tema da pesquisa, temos que todos os entrevistados informaram que as matérias-primas são obtidas de maneira sustentável (Tabela 5).

Tabela 5:

AS MATÉRIAS-PRIMAS SÃO OBTIDAS

DE MANEIRA SUSTENTÁVEL?

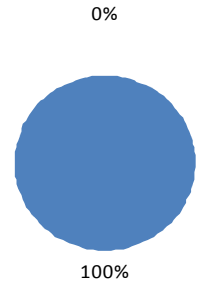


No que se refere a Apoio ou Interesse Local pelo Artesanato temos $80 \%$ de resposta positiva e $20 \%$ de negativa (Tabela 6 ).

Tabela 6:

\section{EXISTE APOIO OU INTERESSE LOCAL} PELO ARTESANATO?

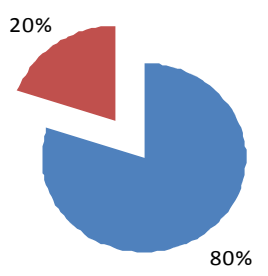

$\mathrm{Na}$ questão econômica, temos que o artesanato produzido pelos artífices tem a finalidade de comercialização, comprovado com $100 \%$ de resposta afirmativa pelos entrevistados (Tabela 7).

Tabela 7:

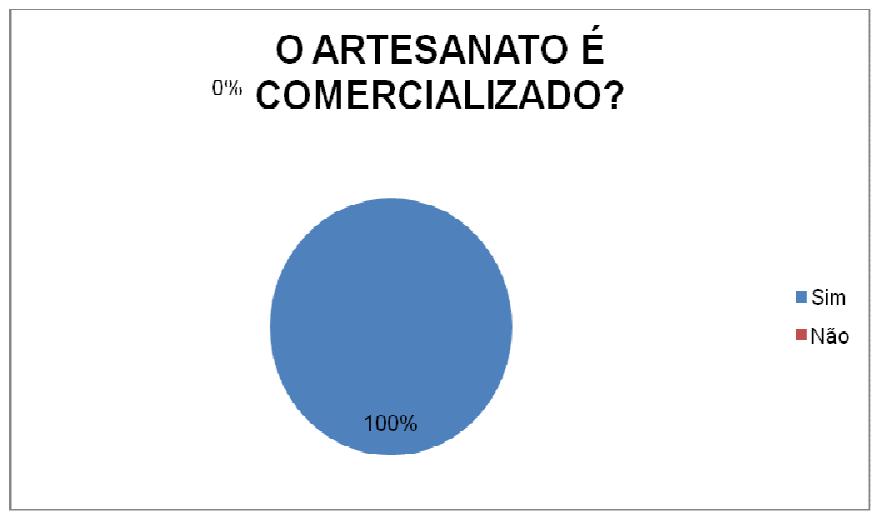

A partir da questão anterior, nota-se que há a produção dirigida para a comercialização, e que, a renda obtida contribui $100 \%$ da renda familiar (Tabela 8 ). 
Tabela 8:

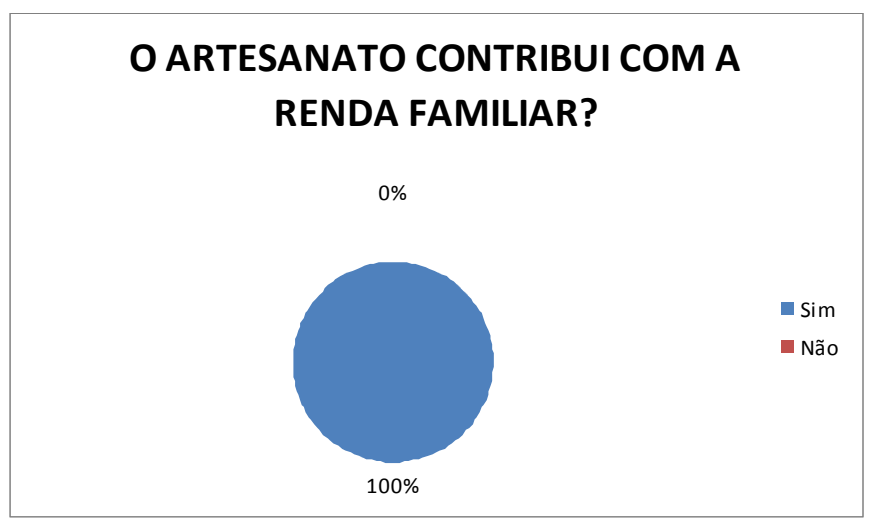

Vê-se também que o percentual de renda advindo do artesanato é considerável pois na faixa 1 (10 a $30 \%$ ) corresponde a $40 \%$, e na faixa 3 (mais de $40 \%$ ) ficou em $60 \%$. Nota-se que na faixa 2 (30 a 40\%) não houve pontuação (Tabela 9).

Tabela 9:

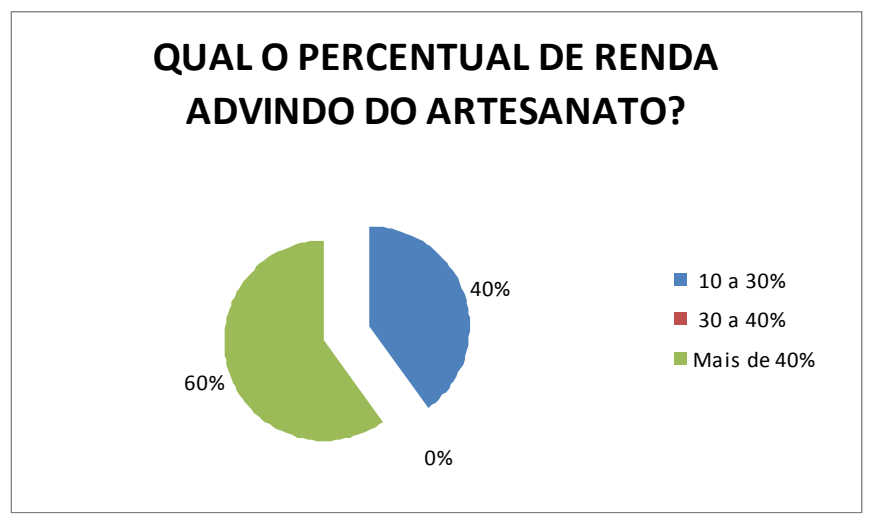

Devido não haver opções de respostas a serem escolhidas pelos entrevistados, foi citado por várias vezes que os principais compradores dos artesãos são os turistas e visitantes, não tendo um dado percentual específico para esta questão (Tabela 10). 
Tabela 10:

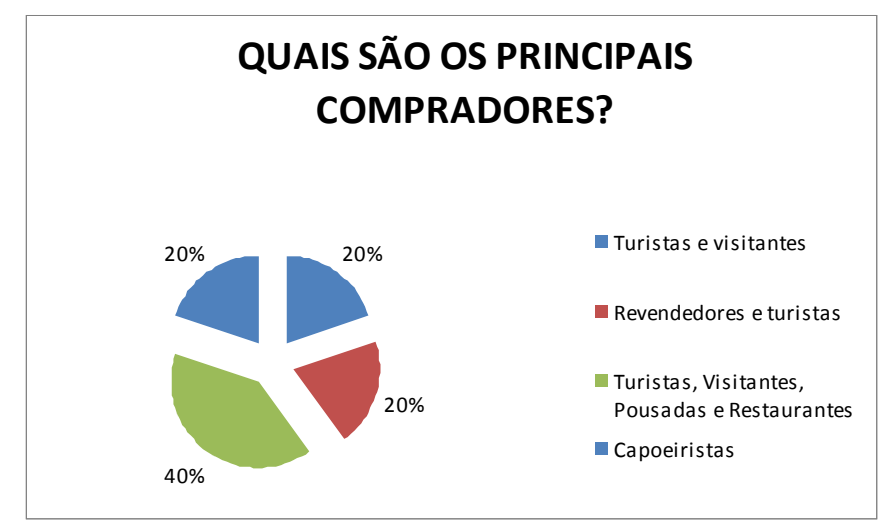

O estudo apontou também que no que se refere a participação de Cursos de Qualificação, 20\% afirmou que já o fez e $80 \%$ respondeu negativamente (Tabela 11).

\section{Tabela 11:}

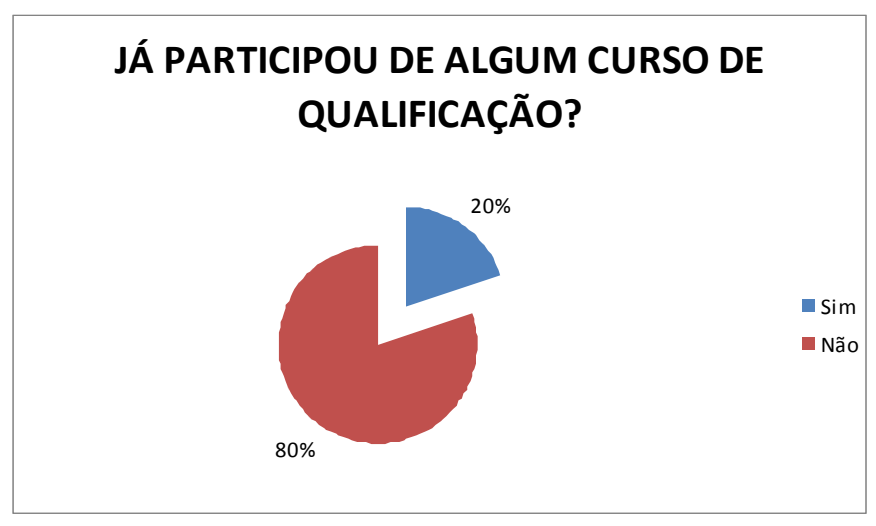

De posse dos dados obtidos a partir das entrevistas empreendidas com os artesãos dos cinco municípios foram identificados os seguintes artesanatos e matériasprimas (Tabela 12): 
Tabela 12:

\begin{tabular}{|c|c|}
\hline \multicolumn{2}{|l|}{ PANELEIRAS - VITÓRIA: } \\
\hline Produtos & Matéria-prima e informações complementares \\
\hline "Vassouras" de muxinga & Para o uso no açoite das panelas de barro \\
\hline Tintura do Tanino & $\begin{array}{l}\text { Corante natural extraído da casca do mangue vermelho a partir do } \\
\text { "descanso" em molho por dois dias em água em um recipiente. }\end{array}$ \\
\hline Panela de barro & $\begin{array}{l}\text { Argila extraída do Vale do Mulembá no Bairro Joana D'arc em } \\
\text { Vitória/ES. }\end{array}$ \\
\hline & $\begin{array}{l}\text { Observação: a madeira utilizada para a queima das panelas } \\
\text { de barro é proveniente de refugo da construção civil local. }\end{array}$ \\
\hline \multicolumn{2}{|l|}{ INDIOS GUARANIS - ARACRUZ: } \\
\hline Produtos & Matéria-prima e informações complementares \\
\hline Arco e flecha & $\begin{array}{l}\text { Madeira forte e boa e a ponta da flecha feita com brajaúba, a fibra } \\
\text { utilizada é a casca da madeira embira. }\end{array}$ \\
\hline Lanças & Confeccionadas com brajaúba ou coqueiro. \\
\hline Chocalhos & Feitos com taquara, coco, cabaça, bambu e sementes. \\
\hline Pau-de-chuva & Produzido com madeira embaúba. \\
\hline Leque & Utiliza-se taquara ou bambu, penas e tinta de urucum. \\
\hline Zarabatana & Feita com bambu grande, oco e reto. \\
\hline Brincos & Produzidos com coquinho de guriri, penas e sementes. \\
\hline Colar & $\begin{array}{l}\text { Feitos com linhas industriais adquiridas no mercado local e dentes } \\
\text { de animais. }\end{array}$ \\
\hline Cocar & Produzidos com penas de aves silvestres e barbantes \\
\hline Prendedor de cabelo & Utilizam-se penas e fibras. \\
\hline Machadinha & Feita com pedra lascada e madeira braúna. \\
\hline Pauzinho de cabelo & Feitos com madeira brajaúba e urá. \\
\hline Cacetete & Produzido com madeira braúna. \\
\hline \multicolumn{2}{|l|}{ ARTESȦO - LINHARES: } \\
\hline Produtos & Matéria-prima e informações complementares \\
\hline Eco-berimbau & Biriba ou Imbiriba ou Beriba \\
\hline \multicolumn{2}{|l|}{ ARTESÃO - SÄO MATEUS } \\
\hline Produtos & Matéria-prima e informações complementares \\
\hline $\begin{array}{l}\text { balaio, abajur,vassoura, fruteira, bolsa de praia, } \\
\text { tapetes de cipó trançado, chapéu, gamela, ca- } \\
\text { noa, pilão, colher de pau e outros. }\end{array}$ & $\begin{array}{l}\text { Cipó jacaré e bambu o qual a partir da coleta de matéria-prima na } \\
\text { mata, ocorre a limpeza e o desfio dos cipós e madeiras, sendo teci- } \\
\text { do os utensílios. }\end{array}$ \\
\hline \multicolumn{2}{|l|}{ ARTESÃO - CONCEIÇÃO DA BARRA: } \\
\hline Produtos & Matéria-prima e informações complementares \\
\hline $\begin{array}{l}\text { Luminárias, porta guardanapos, esteiras, abajur, } \\
\text { vasos, vassoura de guriri, cestas, chapéus, caxixi } \\
\text { (guizo) e cestos de frutas. }\end{array}$ & $\begin{array}{l}\text { O artesão sai à mata para coletar a matéria-prima. De posse dos } \\
\text { bambus e cipós, ele tira a casca, põe para secar e depois deste } \\
\text { processo, iniciam-se os cortes. Daí de posse das fibras são criadas } \\
\text { peças variadas. }\end{array}$ \\
\hline
\end{tabular}


A partir da análise das informações obtidas nas entrevistas foi possível identificar que em grande parte, as matérias-primas são coletadas nas áreas de cobertura vegetal caracterizadas pela Mata Atlântica, a Restinga e o Manguezal. Em Conceição da Barra, a coleta ocorre no entorno do Parque Estadual de Itaúnas, em Aracruz nas matas e mangues da Reserva Indígena da Aldeia Guarani Piraqueaçu, em São Mateus nos fragmentos de Mata Atlântica existente nas propriedades do entorno da Rodovia BR 101 Norte e em Vitória as paneleiras coletam a casca no manguezal urbano da capital. Observa-se um caso particular identificado em Linhares, cujo artífice optou pelo plantio da biriba e com isso, passa a ter uma fonte particular para extração. Já a comunidade indígena destacou a necessidade de buscar alternativas como obter novas sementes para haver o cultivo e possibilitar assim um reforço de opções de coleta, mas que precisa de apoio para viabilizar a proposta.

\section{Conclusão}

O turismo é uma grande oportunidade de geração de trabalho e renda para as comunidades que utilizam de matérias-primas naturais para a confecção de seus artefatos sejam para fins utilitários ou decorativos. Muitos destes são adquiridos por moradores, turistas e visitantes que geram recursos para o artífice local.

Uma observação que deve ser feita é sobre o "Atlas Folclórico do Brasil: Espírito Santo" que em seu capitulo sobre artesanato apresenta uma gama de expressões, o que foi uma grande referência para orientar quanto as categorias que em 1982 puderam ser catalogadas em nosso Estado, a citar: Tecelagem, Cerâmica, Fibras e Trançados, Couros e Peles, Metal, Coco, Madeira, Implementos de Caça e Pesca, Rendas, Bordados e Congêneres e Outros Tipos de Artesanato. Devido à delimitação da presente pesquisa não foi possível comparar os dados disponibilizados no documento em questão, mas perceber a importância do tema e da valorização da atividade.

Os recursos naturais aproveitados pelos artesãos que têm origem na Mata Atlântica e seus Ecossistemas Associados devem ser tratados com sustentabilidade de modo a propiciar o uso das gerações futuras conforme destacado nos textos dos autores consultados.

A fuga do homem da cidade para as áreas não-urbanas é motivada por diversos fatores em períodos como as férias e os finais de semana. Muitos destes têm a oportunidade de conhecer novas realidades culturais quando de sua viagem dispondo da chance de vivenciar novas realidades e costumes. É necessário estimular novas experiências para os turistas a partir de um modelo de sensibilização que possa despertar a preocupação quanto a preservação ambiental e a cultura local através do viés da sustentabilidade. É preciso encontrar um ponto de equilíbrio na relação turismo e meio ambiente de maneira que possa oportunizar o desenvolvimento da comunidade, o aproveitamento dos recursos naturais, a geração de recursos para os moradores e 
a manutenção da cultura do lugar. É essencial que o Estado cumpra seu papel de legislador, planejador e gestor de políticas públicas que possam incentivar o desenvolvimento sustentável através de planos, programas e projetos que tragam benefícios para toda a Cadeia Produtiva do Turismo com o olhar que contemple o equilíbrio ambiental, social, econômico e cultural.

Destaca-se que os objetivos da proposta inicial foram alcançados conforme o levantamento de amostras do artesanato local (embasado na metodologia apresentada) e suas respectivas matérias-primas utilizadas pelos artesãos entrevistados. Sugerem-se como intervenções: mobilizar e sensibilizar os moradores, turistas e visitantes no que se refere à preservação ambiental; propor uma legislação específica que possa educar, fiscalizar e punir as agressões contra o patrimônio natural e seus recursos; assegurar o desenvolvimento econômico local através do desenvolvimento da cultura, do meio ambiente e do turismo com um olhar especial nos impactos que a atividades desenvolvem nas comunidades locais e do entorno; valorizar a cultura local e os meios de perpetuar suas tradições; propor ações de Educação Ambiental além de outras ações necessárias para o desenvolvimento local e a preservação da natureza.

Observa-se que há um grande esforço governamental em organizar a atividade turística a partir do processo de roteirização turística, que em âmbito estadual criou a "Rota do Verde e das Águas", o que favorece na elaboração de roteiros turísticos específicos. Deste modo, cabe também aos operadores turísticos elaborarem roteiros que valorizem as iniciativas com viés sustentável de modo que possa tornar possível garantir os direitos das comunidades locais, preservar o patrimônio do lugar, estimular o desenvolvimento dos destinos turísticos através da gestão responsável dos recursos naturais que são escassos e são utilizados como fontes de subsistência dos artesãos. É necessário implantar novas Unidades de Conservação a partir da legislação vigente e com instrumentos que possam viabilizar o manejo e a conservação dos recursos naturais existentes. Há iniciativas como a encontrada em Linhares que buscam garantir novas fontes de recursos naturais de modo sustentável. O turismo pode ser uma estratégia para levar o turista a adquirir produtos de iniciativas que tem o cuidado com a preservação ambiental, através do Ecoturismo por exemplo. Cabe a cada um dar a sua contribuição.

\section{Referências Bibliográficas}

BRASIL. Ministério do Meio Ambiente. Mata Atlântica. Brasília. 2009. Disponível em: $<$ http://www.mma.gov.br/sitio/index.php? ido=conteudo.monta\&idEstrutura=72\&idMenu=3646>, Acessado em 10 ago 2009, s/d.

BRASIL. Ministério do Turismo. Ecoturismo: orientações básicas. / Ministério do Turismo, Secretaria Nacional de Políticas de Turismo, Departamento de Estruturação, Articulação e Ordenamento Turístico, Coordenação Geral de Segmentação. Brasília: Ministério do Turismo, 2008. 
BRASIL. Ministério do Turismo. Secretaria de Políticas para o Turismo. Programa de Regionalização do Turismo Roteiros do Brasil: Roteirização Turística módulo operacional 7. Brasília, 2005: Ministério do Turismo.

ESPÍRITO SANTO. Secretaria de Estado do Meio Ambiente. Áreas Naturais protegidas do Estado do Espírito Santo. Vitória, 2008. Disponível em: <http:// www.meioambiente.es.gov.br/download/MAPA UC ES.pdf>, Acessado em 26 ago 2009, s/d-a.

ESPÍRITO SANTO. Secretaria de Estado do Turismo. Regiões Turísticas do Espírito Santo. Vitória, 2008. Disponível em: <http://www.turismo.es.gov.br/download/ mapa regiao turistica.pdf> Acessado em 10 ago de 2009, s/d-b.

ESPÍRITO SANTO. Secretaria de Estado do Trabalho, Assistência e Desenvolvimento Social. Instrução Normativa $\mathbf{n}^{\circ} \mathbf{2}$ do Artesanato Capixaba. Classifica os artesãos e suas obras de acordo com as matérias-primas e técnicas principais adotadas, as normas de funcionamento e os critérios adotados para classificação, cadastro, emissão da Carteira do Artesão e da participação em Feiras e Eventos. Vitória, 2009.

INSTITUTO BIO ATLÂNTICA. A Mata Atlântica. Rio de Janeiro. 2009. Disponível em: <http://www.bioatlantica.org.br/mata.asp > Acessado em 10 ago 2009

INSTITUTO JONES DOS SANTOS NEVES. Divisão Regional do Espírito Santo. Vitória, 2008. Disponível em: < http://www.ijsn.es.gov.br/mapas/ esmapas/1.CARACTERIZACAO TERRITORIAL/Limites e Regionalizacoes/ MICRORREGIOES.pdf >. Acessado em 16 ago de 2009

INSTITUTO NACIONAL DO FOLCLORE. Atlas Folclórico do Brasil: Espírito Santo. Rio de Janeiro, Funarte, 1982. 93 p.

MOURA, A. K. C. O mito do desenvolvimento sustentável da atividade turística: uma análise crítica das teorias da sustentabilidade, das políticas públicas e do discurso oficial do turismo na Paraíba. Dissertação apresentada ao Programa Regional de PósGraduação em Desenvolvimento e Meio Ambiente - PRODEMA - Universidade Federal da Paraíba. João Pessoa. 2008

RUSCHMANN, D.V.M. Turismo e planejamento sustentável: a proteção do meio ambiente. Campinas / SP: Papirus, 1997. (Coleção Turismo). 6ª Edição. 2000. 


\section{NOTAS:}

${ }^{1}$ Ecossistemas Associados à Mata Atlântica são a Restinga e o Manguezal.

${ }^{2}$ O natural do Espírito Santo.

${ }^{3}$ Rota Turística: Percurso continuado e delimitado cuja identidade é reforçada ou atribuída pela utilização turística (MTUR, 2005, pg.03).

${ }^{4}$ Espaço geográfico que apresenta características e potencialidades similares e complementares, capazes de serem articuladas e que definem um território (BRASIL, 2005, pg.03). A segmentação é entendida como uma forma de organizar o turismo para fins de planejamento e gestão, e, principalmente, mercadológicos (BRASIL, 2005, pg.15).

${ }^{5}$ Secretaria de Estado do Turismo.

${ }^{6}$ De acordo com a Instrução Normativa $n^{\circ} .2$ do Artesanato Capixaba da SETADES, o artesão é o indivíduo que detém o conhecimento do processo produtivo, sendo capaz de transformar a matéria-prima, criando ou produzindo trabalhos que detenham dimensão cultural, utilizando técnica predominantemente manual, principalmente na fase de formação do produto, podendo contar com auxílio de equipamentos, artefatos e utensílios, desde que não sejam automáticos ou duplicadores de peças.

Mário Vinícius Cinelli Zanetti : Centro Universitário Vila Velha.

Email: mariozaneti@gmail.com

Link para o currículo Lattes: http://lattes.cnpq.br/6652328729680709

Ubirajara Corrêa Nascimento: Centro Universitário de Vila Velha, Faculdade Saberes, e Universidade Gama Filho.

Email: ubirajara.nascimento@uol.com.br

Link para o currículo Lattes: http://lattes.cnpq.br/6946581465877208

Data de submissão: 03 de outubro de 2009.

Data do aceite: 12 de dezembro de 2009 . 